\title{
DO DOCTORS KNOW ENOUGH ON TUBERCULOSIS? A SURVEY AMONG GOVERNMENT MEDICAL OFFICERS IN THE CURATIVE HEALTH SECTOR
}

\author{
Madegedara RMD, Yasaratne BMDG \\ Respiratory Medicine Unit II, Teaching Hospital, Kandy, Sri Lanka
}

\begin{abstract}
Background: Tuberculosis (TB) is a global epidemic with over 2 billion people, equal to one-third of the world's population, are currently estimated to be infected. In Sri Lanka, despite an effective national programme for TB control and mass scale immunoprophylaxis, TB still remains a growing public health issue with over 9000 new cases being detected annually. Studies conducted in many high prevalent settings had clearly shown that the knowledge and practices among many general practitioners and family physicians do not conform to WHO guidelines or expectations. A survey among government medical officers in the curative health sector was carried out with the objective to assess the basic knowledge on tuberculosis (TB) among non-specialist medical officers (MOs).
\end{abstract}

Methodology: We assessed the basic knowledge on TB in five main fields, namely clinical pathology, diagnostic methods, treatment regimens, Direct Observed Treatment Short course (DOTS) and Bacillus of Calmette-Guerin (BCG) vaccination in 355 randomly selected MOs. According to the individual performance, marks were allocated and a grading of poor, average or good was offered for each component. An overall final rank was given to each subject according to the total marks achieved.

Results: Only $27 \%$ had good (marks $>66 \%$ ) overall knowledge. $67 \%$ had average, while $6 \%$ had poor (marks $<33 \%$ ) overall knowledge. Majority had good understanding on clinical pathology and DOTS, but the knowledge was most inadequate with regard to BCG and treatment regimens. Post-intern MOs had a lower understanding on anti-TB medications and different regimens, when compared to intern MOs ( $x 2=8.8047, p=0.012)$, and their knowledge did not improve with service experience. MOs attached to out-patient departments and surgical units seem to be in need of extra attention.

Conclusion: The knowledge on basic aspects of TB is not satisfactory among most of the MOs. Applicability of targeted awareness and continuation of medical education programmes, assessment schemes, appraisal systems and antibiotic regulation and prescription policies for the local setup should be explored.

Keywords: Tuberculosis, Sri Lanka, TB, Knowledge, Medical officers

\section{INTRODUCTION}

Tuberculosis (TB) is a global epidemic with over 2 billion people, equal to one-third of the world's

\footnotetext{
Correspondence:

Dr. Dushantha Madegedara

Consultant Respiratory Physician

Teaching Hospital, Kandy, Sri Lanka.

Email:dmadegedara@yahoo.com
}

population, are currently estimated to be infected, with 9.4 million new TB cases identified worldwide and 1.8 million deaths annually. In 2008 the SouthEast Asia Region accounted for $34 \%$ of incident cases globally. ${ }^{1}$ In Sri Lanka, despite an effective national programme for TB control and mass scale immunoprophylaxis, TB still remains a growing public health issue with over 9000 new cases being detected annually. ${ }^{2}$ 
Despite the enormity of the issue and constant effort of World Health Organization (WHO), understanding and awareness on many aspects of $T B$, among the general public as well as many health care professionals, remains hesitant. Surveys carried out worldwide assessing not only the knowledge, but also attitude and practices of health care workers, have identified calamitous deficiencies warranting a well coordinated global effort in order to achieve WHO stop TB partnership targets. ${ }^{3,4,5}$

Studies conducted in many high prevalent settings had clearly shown that the knowledge and practices among many general practitioners and family physicians do not conform to WHO guidelines or expectations. ${ }^{6,7}$ This, among many others, had been identified as an important iatrogenic factor which had lead to the identification of multi-drug resistant cases from over 100 countries and extensive drug resistant cases form 57 countries to date. ${ }^{8}$

Considering the rising incidence of resistant TB cases in Asian continent, Sri Lanka should be ever vigilant to keep the disease under control and to maintain its very low incidence of resistant cases. Further to a dedicated national programme for tuberculosis control (NPTC) and the supervision of every TB patient by a respiratory physician or qualified personnel, it is equally important for all of the health care personnel to be conversant with many basic aspects of tuberculosis. Intention of this limited survey was to assess the basic knowledge regarding few major aspects of tuberculosis among a group of Sri Lankan medical officers in the curative sector. The objectives of the survey were to evaluate the knowledge on tuberculosis among a representative sample of medical officers in the curative sector, to identify any categories of medical officers requiring special awareness programmes and to provide background information for the NPTC to plan out future training campaigns.

\section{METHODOLOGY}

\section{Design and setting}

We carried out a questionnaire based survey in two districts of the country; namely in Kandy and Kegalle. The study was conducted in General
Hospitals Kandy and Kegalle and randomly selected secondary health care centres consisting of Base Hospitals Mawanalla, Karawanalla, Warakapola and District Hospital Rambukkana.

\section{Recruitment of participants to the survey}

A total of 355 medical officers were selected to participate in the survey. 200 were from Kandy district while 155 were from Kegalle district, proportionate to the employee number in each hospital concerned. The sample was selected using stratified randomization methods to represent different units in each hospital and to represent different categories of medical officers.

\section{Data acquisition}

A self administered questionnaire with ten multiple response questions was used as the data collecting tool (annexure 1). This was pretested at a pilot study conducted in early 2007 at Teaching Hospital, Kegalle.

Data collection was carried out in January to March 2007 in Kandy district and January to April 2009 in Kegalle district. We took special precautions to avoid possible re-recruitment of participants, since the study was carried out in two steps. Each selected participant was handed over the questionnaire after explaining the purpose of the study and advised to respond in the presence of the investigator. Average time taken by the participants was around fifteen minutes. Each answer sheet was checked twice and marks allocated by two independent investigators.

\section{Assessment of knowledge}

In this survey the investigators concentrated on the basic knowledge in five main fields about tuberculosis, namely clinical pathology, diagnostic methods, treatment regimens, direct observed treatment short course (DOTS) and Bacillus of Calmette-Guerin (BCG) vaccination. The questionnaire was designed to cover the above aspects. 


\begin{tabular}{|c|c|c|c|c|}
\hline $\begin{array}{c}\text { Topic \& } \\
\text { Question } \\
\text { numbers }\end{array}$ & $\begin{array}{l}\text { Total } \\
\text { marks }\end{array}$ & Poor & Average & Good \\
\hline $\begin{array}{l}\text { Clinical } \\
\text { Pathology } \\
\text { (Q1,2,3) }\end{array}$ & $3 \times 3=9$ & $\leq 3$ & $4-6$ & $7-9$ \\
\hline $\begin{array}{l}\text { Method of } \\
\text { Diagnosis } \\
(Q 4,10)\end{array}$ & $3 \times 2=6$ & $\leq 2$ & $3-4$ & $5-6$ \\
\hline $\begin{array}{l}\text { Treatments } \\
(\mathrm{Q} 6,7,8)\end{array}$ & $3 \times 3=9$ & $\leq 3$ & $4-6$ & $7-9$ \\
\hline DOTS (Q9) & $3 \times 1=3$ & 1 & 2 & 3 \\
\hline BCG (Q5) & $3 \times 1=3$ & 1 & 2 & 3 \\
\hline
\end{tabular}

According to the individual performance, marks were allocated and a grading of poor, average or good was offered for each component (Table 1). The overall final ranking was given according to the total marks achieved in all components (Table 2).

Table 2. Final ranking of knowledge according to total marks obtained

\begin{tabular}{|l|l|}
\hline Total marks (out of 30 ) & Final ranking \\
\hline$\leq 10$ & Poor \\
\hline $11-20$ & Average \\
\hline $21-30$ & Good \\
\hline
\end{tabular}

\section{Data analysis}

Data were entered in to an MS Excel 2003 data sheet and analyzed using MS Excel and SPSS 12.0 statistical software. Chi square test was used where appropriate in calculating statistical significance at a $5 \%$ significance level at relevant degrees of freedom.

\section{Ethical considerations and confidentiality}

All participants to this survey are voluntary medical officers. The informed consent was taken from each participant after explaining the objectives of the survey by the investigators. All answered questionnaires were kept securely with access only to study group personnel. Name and other specific particulars of the participants, which will lead in to their identification, were not included in the survey.

\section{RESULTS}

We recruited a representative group of 286 post-intern MOs and 69 intern MOs. The overall knowledge in $67 \%$ was average, while $27 \%$ had good overall knowledge and $6 \%$ were found to have poor overall knowledge. When the responses for individual components were considered, the knowledge was most inadequate regarding BCG vaccination and treatment regimens, while majority had good understanding on clinical pathology and DOT strategy (Figure 1).

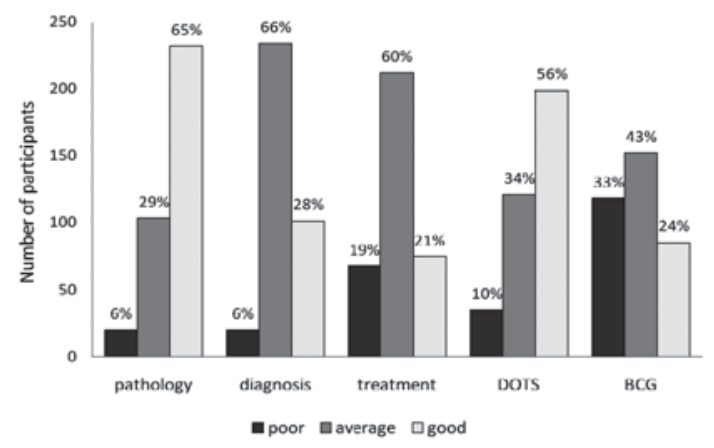

Figure 1. Comparison of the grades of knowledge achieved by th e participants for the different components

$61 \%$ of MOs were having the misconception that BCG vaccination would prevent children from acquiring pulmonary TB, while $37 \%$ had poor understanding on the need for BCG revaccination in childhood. Many were not familiar with the different treatment regimens and their indications, and $24 \%$ were not aware on the use of levofloxacin and clarythromycin as second line anti-tubercular therapy. $10 \%$ were not confident regarding the diagnostic value of Mantoux test.

We further compared the knowledge among different categories of MOs. Intern MOs had better overall understanding than post intern MOs (Figure $2 \chi^{2}=8.8047, p=0.012$ ). This difference was mainly observed in relation to anti-TB medication and treatment regimens. 


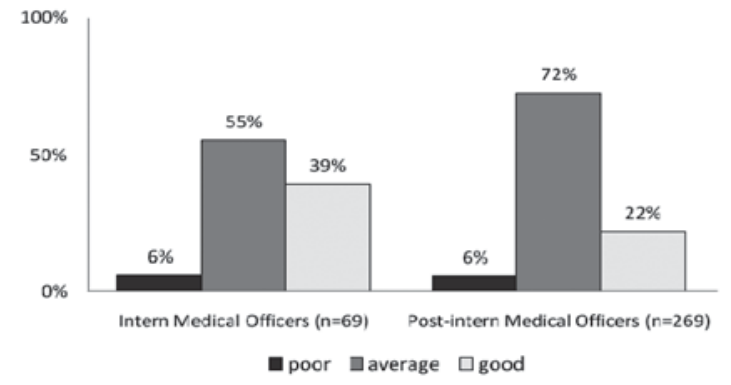

Figure 2. Comparison of knowledge (final overall ranking) between intern and post-intern medical officers

The specialties or units, to which MOs were attached, were categorized in to four. The medical group consisted of general medicine, general paediatrics and allied specialties, while the surgical group consisted of general surgery, allied specialties and gynaecology and obstetrics. Out patient department (OPD) was considered a separate group while anaesthesia, intensive care medicine and radiology units were considered together. Among them we noted that OPD and surgical categories had the highest number of poor grades, $8.6 \%$ and $7.5 \%$ respectively, even though the differences were not statistically significant (Figure $3 \chi^{2}=9.7121, p=0.137$ ).

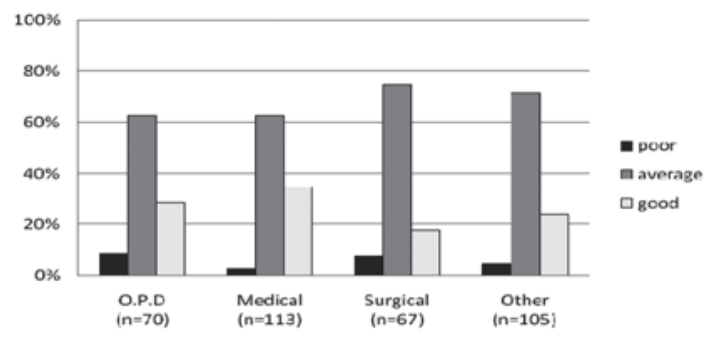

Figure 3. Comparison of knowledge (final overall ranking) among medical officers attached to different specialties / units

There was no significant difference among the ranks achieved by MOs with increasing service experience (Table 03; $\chi^{2}=2.3048, p=0.889$ ).

Table 3. Final ranking of knowledge among medical officers with different service experience $(x 2=2.3048, p=0.889)$

\begin{tabular}{|c|c|c|c|c|}
\hline $\begin{array}{c}\text { Service } \\
\text { experience }\end{array}$ & Total $(\mathrm{n})$ & Poor & Average & Good \\
\hline Below 3 years & 171 & $5 \%$ & $68 \%$ & $26 \%$ \\
\hline 3 to 6 years & 78 & $6 \%$ & $67 \%$ & $27 \%$ \\
\hline 6 to 9 years & 53 & $2 \%$ & $68 \%$ & $30 \%$ \\
\hline Over 9 years & 52 & $8 \%$ & $63 \%$ & $29 \%$ \\
\hline
\end{tabular}

\section{DISCUSSION}

Results showed that around three-fourths of the group were unable to achieve a minimum of $66 \%$ of the answers correct. This implies that the average knowledge on basic aspects of the disease is not satisfactory among most of the MOs. Since many post-intern MOs serve as primary physicians in the private sector of the country, it is important for these first contact medical persons to have a sound working knowledge on this common and growing health issue.

The observations that the interns having better understanding on treatment aspects and that the knowledge not improving with length of service, raise the issues of lack of continuing education after graduation and lack of continuous assessment programmes in general. Recently NPTC has started a tuberculosis awareness programme for all preintern medical graduates, which will somewhat help to bridge this gap, but further campaigns targeting post-interns with special attention to OPDs and surgical units would be invaluable. Furthermore undergraduate medical curricula could be revised in order to minimize these deficiencies.

Poor understanding on anti-TB medications and different treatment regimens was highlighted in this survey. This necessitates the proposal of certain administrative legislations. Commencing and continuing ATT is currently under specialist supervision and we would be well advised to strictly adhere to that practice, as lessons should be learnt from the practices of other countries with high prevalence of resistant TB. ${ }^{9,10,11}$ Antibiotic misuse is a major worldwide concern affecting TB control. Since irrational prescription and over the counter use of antibiotics is not uncommon in the country, we recommend for establishment of national antibiotic regulation and prescription policies. Use of important second line anti-tuberculosis antibiotics in general practice should be restricted to specialist authorization.

This study did not explore doctors' attitudes towards the disease, which would be interesting to look into since TB still carries a significant social stigma in 
the local community. Another limitation was that the study was carried out in two phases due to practical inconveniences, which necessitated special precautions to avoid re-engaging same participant in both phases due to possible transfer among work stations. Nevertheless, this is not expected to interfere with the results as we do not observe a noteworthy change in the local education system or the hospital practices with regard to TB, during the past few years.

As the country has many primary care general practitioners (GPs) not attached to Government hospitals, it would be prudent to carry out a similar survey among them to identify any similar deficiencies. Awareness programmes may be organized jointly by NPTC and GP associations. Applicability of Continuation of Medical Education (CME) appraisal systems to both Government and non-Government health sectors in the country, followed by a well structured assessment programme should be explored ${ }^{12}$. Concurrently, hospitals should be provided with necessary facilities such as libraries, internet access, etc.

\section{CONCLUSION}

The knowledge on basic aspects of TB is not satisfactory among most of the MOs. We propose to conduct more targeted awareness programmes and to provide with necessary material and facilities to upgrade knowledge. Applicability of Continuation of Medical Education appraisal systems to the country with well structured assessment programmes should be explored. We recommend for antibiotic regulation and prescription policies and specialist supervision of all TB cases.

\section{REFERENCES}

1. World Health Organization. Global Tuberculosis Control 2009. A Short Update to the 2009 report. WHO publications, December 2009.

2. National programme for tuberculosis control and chest diseases. General manual for tuberculosis control. 2nd ed. Ministry of Health, Sri Lanka: 2005.

3. Corless JA, Stockton PA, Myers SB, Davies PD. A worldwide internet survey of public knowledge about tuberculosis. Respir Med 2002;96:59-60.

4. Singla N, Sharma PP, Singla R, Jain RC. Survey of knowledge, attitudes and practices for tuberculosis among general practitioners in Delhi, India. Int J Tuberc Lung Dis.1998;2:384-9.

5. World Health Organization. The Stop TB Partnership; The Global Plan to Stop TB (20062015). WHO publications; January 2006.

6. Hong YP, Kwon DW, Kim SJ, Chang SC, Kang MK, et al. Survey of knowledge, attitudes and practices for tuberculosis among general practitioners. Tuber Lung Dis 1995;76: 431-5.

7. Hashim DS, Al Kubaisy W, Al Dulayme A. Knowledge, attitudes and practices survey among health care workers and tuberculosis patients in Iraq. EMHJ 2003;9:718-731.

8. World Health Organization. Multidrug and extensively drug-resistant TB (M/XDR-TB): 2010 Global Report on surveillance and Response. WHO publications; March 2010.

9. Uplekar MW, Rangan S. Private doctors and tuberculosis control in India. Tubercle and Lung Disease 1993;74:332-7.

10. UplekarMW, Shepard DS. Treatment of tuberculosis by private general practitioners in India. Tubercle 1991;72:284-290.

11. Ollé-Goig JE, Cullity JE, Vargas R. A survey of prescribing patterns for tuberculosis treatment amongst doctors in a Bolivian city. The Int J Tuberc Lung Dis 1999;3:74-78.

12. Davis DA, Thomson MA, Oxman AD, Haynes RB. Evidence for the effectiveness of CME. A review of 50 randomized controlled trials. JAMA 1992; 268:1111-7. 